\title{
A Single-Blinded Randomized Controlled Trial of Mesenchymal Stem Cell Therapy for the Treatment of Osteoarthritis of the Knee with Active Control
}

\author{
Ruane $\mathrm{JJ}^{1}$, Ross $\mathrm{A}^{2}$, Zigmont $\mathrm{V}^{2}$, McClure $\mathrm{D}^{1}$, Gascon $\mathrm{G}^{2}$
}

\begin{abstract}
Background:

Osteoarthritis is most prevalent in the knee and drives the growing incidence of total knee arthroplasty. There is a need to explore non-surgical treatment options to increase the portfolio of alternatives available. The study aimed to determine the clinical response to an autologous bone marrow aspirate concentrate (BMAC) and platelet-rich plasma (PRP) intra-articular injection compared to an active comparator.
\end{abstract}

\section{Methods:}

The study was a prospective, single-blinded, randomized controlled pilot study. Participants with diagnosed knee osteoarthritis were allocated to one of two treatment groups to receive a BMAC injection immediately followed by a PRP injection or a single injection of Gel-One ${ }^{\circledR}$ crosslinked hyaluronate (HA). Outcomes were assessed at 3, 6, and 12 months post-treatment.

\section{Results:}

Significant improvements were observed in both treatment groups for all Knee Injury and Osteoarthritis Outcome Score (KOOS) subscales with the exception of the symptoms assessment at 12 months in the HA group. BMAC KOOS scores peaked at 12 months, while HA KOOS scores generally peaked at 6 months. The gap in mean scores at 12 months in favor of the BMAC group did not reach statistical significance. Secondary outcomes included a greater reduction in pain at 12 months in the BMAC group (-3.13 points; 95\% CI: -3.96, -3.29) compared to the HA group (-1.56 points; $95 \% \mathrm{CI}:-2.59,-0.53 ; \mathrm{p}=0.02)$ via the numeric pain rating scale.

\section{Conclusions:}

Results demonstrate that both treatment groups experienced clinically and statistically significant improvement across the KOOS subscales. While BMAC has shown promise in the treatment of knee OA, there is a need for multi-center investigations with larger sample sizes, an extended follow-up, and placebo-based control. ClinicalTrials.gov Identifier: NCT02958267

Key Words: Knee osteoarthritis; Regenerative medicine; Orthobiologics; Cellular therapy; Regenerative orthopedics

\section{Introduction}

Arthritis has been identified as one of the leading causes of disability in the United States ${ }^{[1]}$ affecting approximately 1 of 5 adult males and approximately 1 of 4 adult females. ${ }^{[1,2]}$ Osteoarthritis (OA), the most common form of arthritis ${ }^{[3]}$, is most prevalent in the knee and accounts for $31 \%$ of all OA-related medical visits ${ }^{[4]}$. The lifetime risk of symptomatic knee OA is nearly $45 \%^{[5]}$ and the growing life expectancy will continue to rapidly increase the cases of knee OA and subsequent substantial economic burden to society, payers, and patients ${ }^{[6]}$.

Stepwise exposure to various non-surgical therapies is critical in the management of symptomatic knee OA. Available evidencebased guidelines including the American College of Rheumatology, the American Academy of Orthopedic Surgeons, and the Osteoarthritis Research Society International suggest that patients begin management with non-surgical options, while progressing to a surgical intervention in cases where non-surgical treatment fails to relieve the underlying symptoms ${ }^{[7-9]}$. The accepted option for knee OA when non-surgical options fail is total knee arthroplasty (TKA). The prevalence of knee arthroplasty increased $300 \%$ in the United States from 1990 to $2010^{[10]}$. Considering the aging demographic in the United States, the demand for primary TKA is expected to increase by another twoto seven-folds by 2030 with associated costs increasing exponentially ${ }^{[11,12]}$. The growing $\operatorname{costs}^{[13]}$, added to the risk of complications associated with $\mathrm{TKA}^{[14]}$, demonstrates the importance of evaluating lower risk and lower cost options to manage the condition with intent to delay the need for surgical intervention or avoid surgical intervention in a subset of the population.

Conservative treatment options such as physical exercise and weight loss are recommended as an initial option to OA. ${ }^{[7-9]}$ Pain associated with knee OA is often treated with non-steroidal 
anti-inflammatory drugs (NSAIDs). Intra-articular (IA) therapies including hyaluronic acid and corticosteroid injections are commonly deployed ${ }^{[15,16]}$. However, limitations exist regarding each of the commonly utilized non-surgical options. Not all individuals with presence of knee OA have needs for additional prescriptive or guided exercise, or require weight loss. IA steroid injections are commonly used to manage the pain and effusion accompanying an acute exacerbation of knee $\mathrm{OA}$, as opposed to offering a long term management strategy. Available evidence demonstrates symptom reduction with hyaluronic acid and corticosteroid injections in the short term ${ }^{[16-18]}$; but, evidence does not consistently support long term improvement and certainly not reversal of the disease state ${ }^{[16-18]}$. Specifically, the efficacy of hyaluronic acid has been shown to be clinically comparable to NSAIDs in the short-term ${ }^{[17]}$. The use of NSAIDs have come under intense scrutiny with respect to their safety in patients with cardiovascular disease as NSAIDs can increase the risk of having a heart attack or stroke ${ }^{[2]}$. Since nearly one in two Americans with heart disease also have arthritis ${ }^{[3]}$, there is a growing necessity to apply non-drug therapies in the treatment of knee OA. The limitations noted affect the availability of treatments for individuals with knee OA creating a continuous need to evaluate additional non-surgical treatment options to increase the overall portfolio of alternatives available.

\section{Background and objectives}

Orthobiologics (also termed regenerative therapies) provide a mechanism to apply non-drug treatments, and some treatment approaches have gained traction in the literature. Specifically, mesenchymal stem cell (MSC) therapy has shown early promise in the non-surgical treatment of chronic degenerative disease such as $\mathrm{OA}^{[20,21]}$. MSCs can be obtained by way of bone marrow aspirate concentrate (BMAC) or adipose tissue. Available systematic reviews and/or meta-analyses generally demonstrate early benefits in the application of orthobiologics for $\mathrm{OA}^{[22-25]}$. Studies specifically evaluating IA application of $\mathrm{BMAC}^{[26-28]}$ or adipose-derived $\operatorname{MSCs}^{[29,30]}$ have demonstrated consistent improvement in pain and function at follow-up time points ranging from 6-24 months. However, the benefits of such treatments are still interpreted cautiously as limitations exists including heterogeneity of outcome measures $^{[22]}$, heterogeneity of dosing ${ }^{[22]}$ and source of mesenchymal stem cells (i.e., bone marrow, adipose tissue, allo- vs. autograft), risk of bias ${ }^{[23]}$, and a lack of large scale studies ${ }^{[24]}$. Also, there are a paucity of active comparator trials that demonstrate superiority of BMAC over currently available injectable therapies. In a recent report, Anz et al. concluded that while both BMAC and PRP were clinically effective at 12 months, BMAC failed to demonstrate superiority ${ }^{[31]}$. Similarly, Shapiro et al. found improvement in both groups but no significant difference between BMAC and saline ${ }^{[32]}$. Vega et al. has demonstrated greater functional improvement form culture-expanded, allogeneic MSCs compared to HA; however, the HA group also demonstrated reduced pain scores at 12 months $^{128]}$. Our study adds to the pool of available active comparator trials.

The purpose of this study was to determine the clinical response to an autologous BMAC and subsequent PRP intra-articular (IA) injection for knee $\mathrm{OA}$ at 1 year versus an active comparator group receiving a single injection of Gel-One ${ }^{\circledR}$ Cross-Linked hyaluronate (Zimmer Biomet, Warsaw, IN) on the following primary and secondary clinical outcomes:

Primary: Change in knee pain, symptoms, function in activities of daily living, function in sport and recreation, and knee-related quality of life as measured by the Knee injury and Osteoarthritis Outcome Score (KOOS) at 3, 6, and 12 months following treatment with respect to baseline.
Secondary: Change in knee pain as measured by the Numeric Pain Rating Scale (NPRS) at 3, 6, and 12 months following treatment with respect to baseline.

Secondary: Change in global physical and mental health as measured by the Patient Reported Outcomes Measurement Information System (PROMIS ${ }^{\circledR)}$ Global Health scale v1.1 at 3, 6, and 12 months following treatment with respect to baseline.

\section{Materials and Methods}

\section{Trial Design}

The study was designed as a prospective, single blind, randomized controlled pilot study, in which a 1:1 randomization method was utilized to ensure an equal allocation to each treatment arm. The principal investigator and study staff were blinded to the randomization schedule with the exception of the research team member (VZ) performing the statistical analyses and who was not involved in recruitment, enrollment, patient care activity, or data collection.

The study was registered on ClinicalTrials.gov (Identifier: NCT02958267) and reviewed and approved by the organization's Institutional Review Board.

\section{Participants}

All enrollment, treatment, and follow-up visits by trial participants were completed at the Ohio Health McConnell Spine Sport and Joint Center - a non-surgical orthopedic clinic in Columbus, Ohio. Potential patients were screened based on inclusion and exclusion criteria (Table 1) and those who satisfied the criteria were introduced to the trial.

Interested patients who then provided informed consent were enrolled. Enrolled patients completed the baseline primary and secondary outcome tools, and a survey to collect relevant past medical history regarding the patient's knee to be treated. Other predetermined baseline demographic information was obtained from the patient's medical record. A flow diagram illustrating patient enrollment and follow-up can be found in Figure 1.

\section{Interventions}

Following the completion of baseline forms, patients were allocated to one of the two treatment groups as follows:

Group A (BMAC): BMAC IA injection immediately followed by PRP IA injection; Group B (HA): Gel-One ${ }^{\circledR}$ Cross-Linked Hyaluronate injection. Baseline demographic and clinical characteristics for each treatment group can be found in Table 2.

Patients allocated to BMAC underwent a venous blood draw and subsequent complete blood count to determine the pre-procedure platelet count. The treatment date, regardless of group allocation, was scheduled and completed within 30 days of the baseline visit. Patients allocated to BMAC were also instructed to discontinue use of any NSAIDs or oral corticosteroids for 2 weeks prior to the planned treatment date.

The intervention for both treatment groups was performed by the principal investigator. For BMAC preparation, the patient was positioned in prone. Sixty $\mathrm{ml}$ of bone marrow was aspirated into $10 \mathrm{cc}$ syringes from the posterior superior iliac crest using the rapidpull technique, and handled by the clinic staff utilizing a BC60 PURE BMC $®$ Concentrating System $60 \mathrm{ml}$ single use 
Table 1: Inclusion and exclusion criteria

\begin{tabular}{|c|c|}
\hline $\begin{array}{l}\text { - Age } 40-70 \text { years old } \\
\text { - Diagnosed with knee OA based on the American College of } \\
\text { Rheumatology criteria } \\
\text { - KL grade } 1-3 \text { based on a radiograph within } 6 \text { months of } \\
\text { enrollment } \\
\text { - Symptomatic evidence of tibiofemoral OA for } \geq 6 \text { months } \\
\text { prior to enrollment } \\
\text { - Pain level to target knee defined as moderate over the } \\
\text { previous } 1 \text { week } \\
\text { - Previous trial of a minimum of } 6 \text { weeks of conservative } \\
\text { therapy including physical therapy, weight loss, anti- } \\
\text { inflammatory medication, or injection therapy }\end{array}$ & 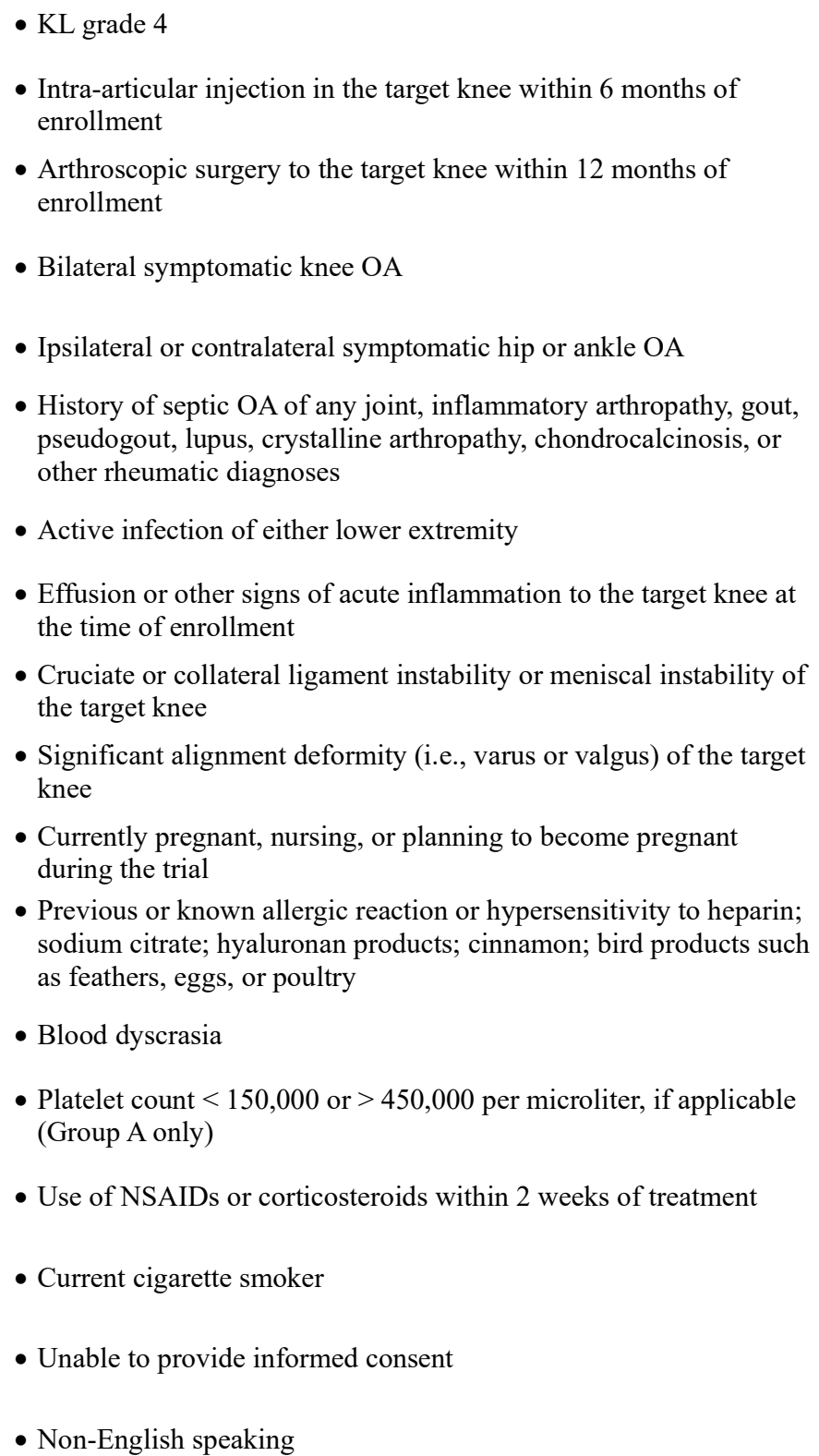 \\
\hline
\end{tabular}

$\mathrm{OA}=$ Osteoarthritis, $\mathrm{KL}=$ Kellgren-Lawrence, NSAID = Non-steroidal Anti-inflammatory Drug 
Figure 1: CONSORT flow diagram

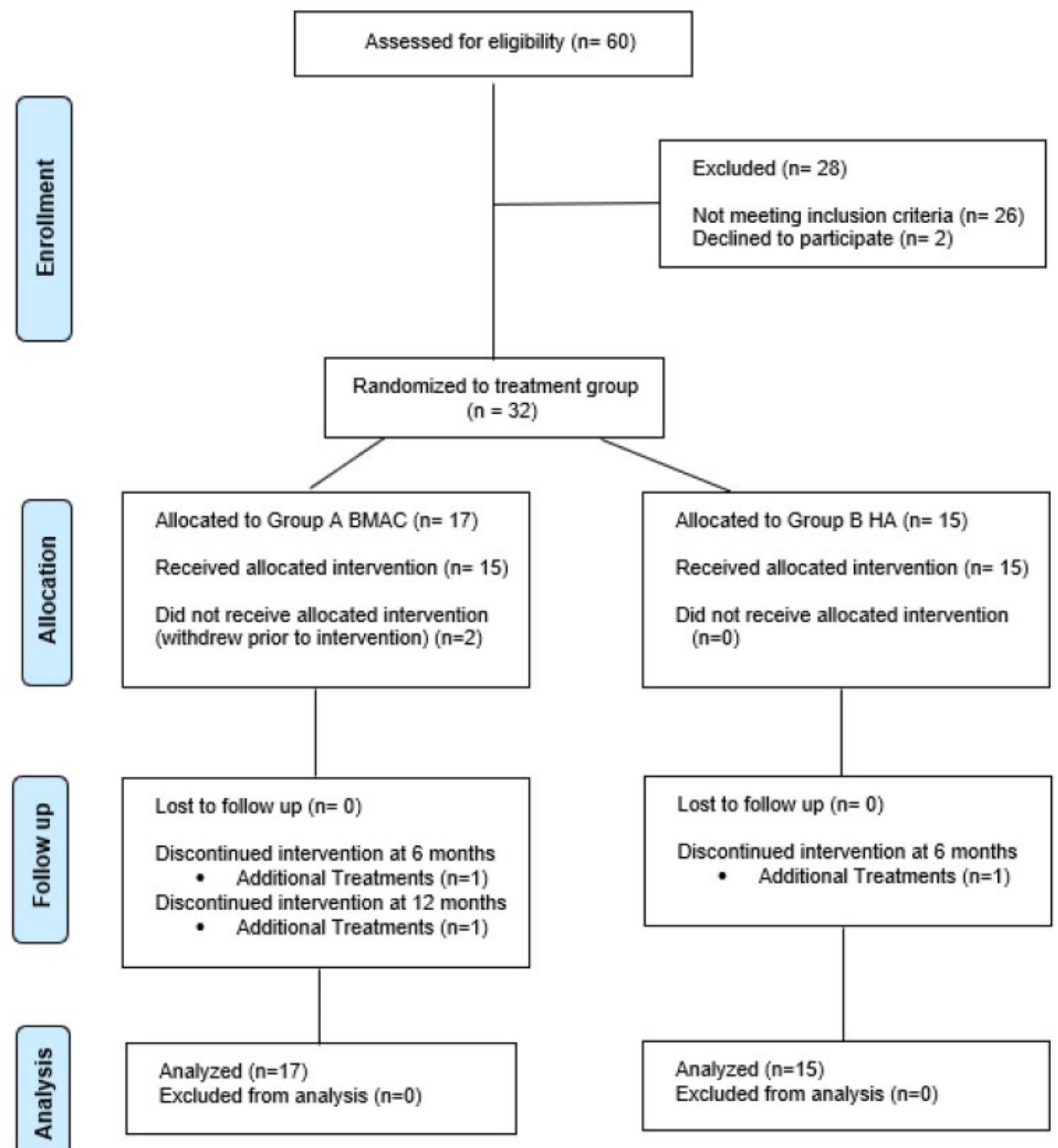

Figure 1: CONSORT flow diagram

disposable kit (EmCyte Corporation, Fort Meyers, FL, USA). The bone marrow was aspirated through a single site portal using a $\mathrm{T}$ handle Jamshidi ${ }^{\mathrm{TM}}$ bone aspiration needle (Becton, Dickinson and Company, Franklin Lakes, NJ, USA). Ultrasound was used to localize the site of aspiration. The limited aspiration was performed under a local anesthetic. The bone marrow was then transferred to the Executive Series Centrifuge II (EmCyte Corporation, Fort Meyers, FL, USA) for centrifugation and resulting bone marrow cell concentration. The concentration process yielded approximately 5-6 $\mathrm{ml}$ of stromal fluid to be used for injection, under ultrasound guidance, into the patient's target knee by the physician. Immediately following the injection of the concentrated cells, 4-5 $\mathrm{ml}$ of previously separated PRP was injected under ultrasound guidance to the subject's target knee (preparation described below) by the physician. For PRP preparation, $60 \mathrm{ml}$ of venous blood was withdrawn from either upper extremity by the clinic staff. The PRP was handled using an AB60 Pure, AcCELLerated Biologics 60mL PURE Concentrating System single use disposable kit (AcCELLerated Biologics, Tequesta, FL, USA).

In the active control group, patients received a single injection of Gel-One ${ }^{\circledR}$ Cross-Linked Hyaluronate into the target knee. After identifying anatomical landmarks and marking the injection site, the area was carefully prepared with a chlorhexidine solution and allowed to dry. The prepared area was swabbed with alcohol. Skin was anesthetized with a vapo-coolant spray for 3-5 seconds. Immediately after evaporation, a needle was advanced to the target area and placement was verified using real time ultrasound guidance. Introduction of the injectate ( $3 \mathrm{ml}$ syringe of Gel-One ${ }^{\circledR}$ $1 \%$ solution $[10 \mathrm{mg} / \mathrm{ml}], 30 \mathrm{mg}$ total hyaluronan) was completed, while pre-injection aspirations were carried out if clinically indicated. 
Subsequently, patients in each group had an identical course of follow-up instructions and visits. Patients were given post-procedure instructions including general recommendations to increase rest and reduce excessive impact over the 48 hours following treatment, while using acetaminophen or ice as needed to address soreness from the IA injection. Patients were scheduled for follow-up visits at approximately 2 weeks (clinical follow-up with the physician performing the procedure), 3 months (clinical follow-up with the physician, and completion of outcome assessments), 6 months (completion of outcome assessments), and 12 months (completion of outcome assessments). The outcomes assessor, who was blinded to treatment allocation throughout the duration of the study, was present for the collection of primary and secondary outcomes of all patients.

Study data were collected and managed using REDCap electronic data capture tools hosted at OhioHealth Corporation. ${ }^{[33]}$ REDCap (Research Electronic Data Capture) is a secure, web-based application designed to support data capture for research studies, providing 1) an intuitive interface for validated data entry; 2) audit trails for tracking data manipulation and export procedures; 3 ) automated export procedures for seamless data downloads to common statistical packages; and 4) procedures for importing data from external sources.

Table 2: Baseline descriptive information of each treatment group

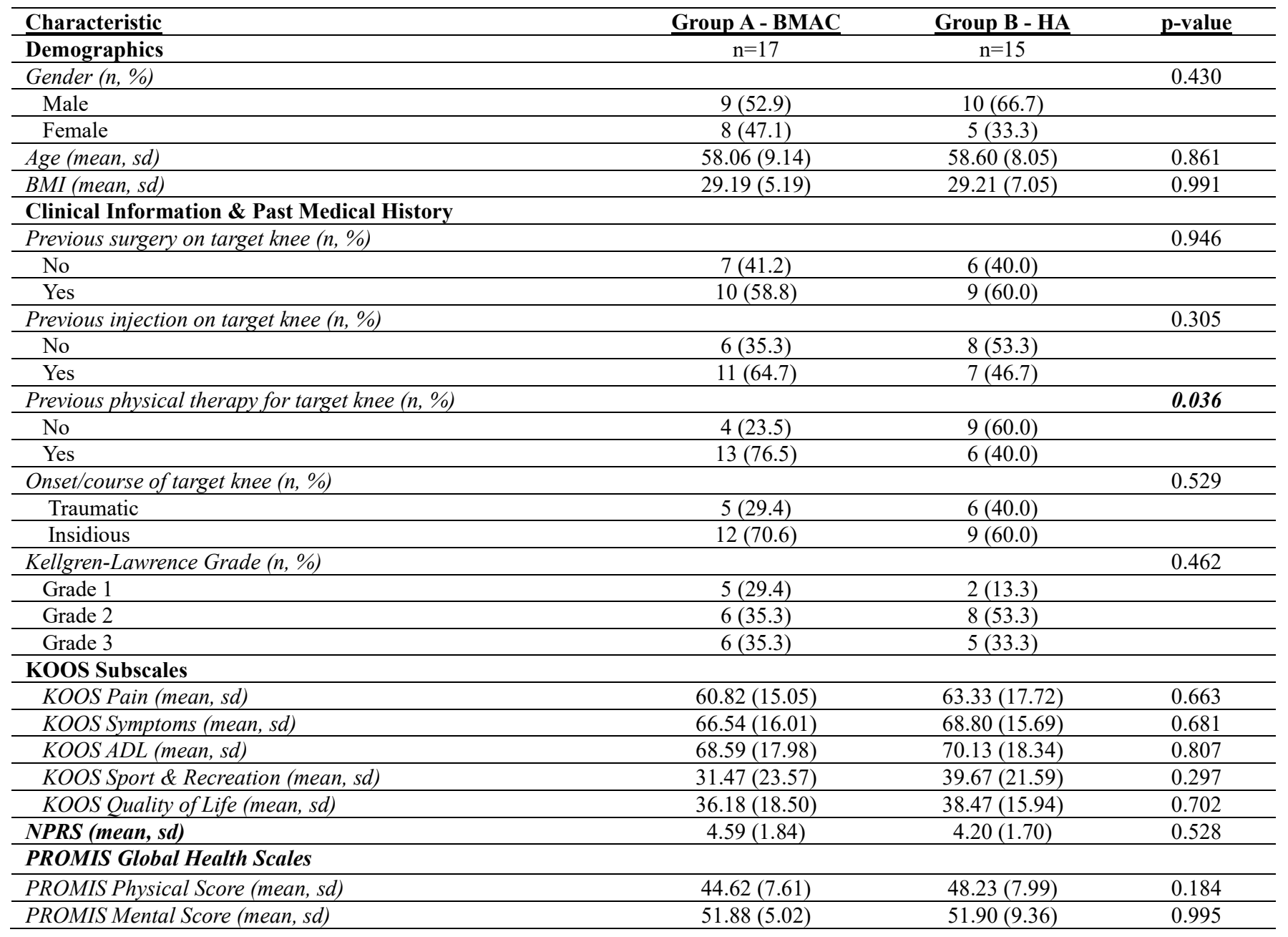

$\mathrm{HA}=$ hyaluronic acid, in this case, Gel-One ${ }^{\circledR}$ Cross-Linked Hyaluronate; $\mathrm{BMI}=$ body mass index; $\mathrm{SD}=$ standard deviation; $\mathrm{KL}=\mathrm{Kellgren}$ Lawrence; $\mathrm{PT}=$ physical therapy; $\mathrm{K} / \mathrm{mcl}=$ thousands per microliter; KOOS $=$ Knee injury and Osteoarthritis Outcome $\mathrm{Score}$; ADL $=$ activity of daily living; QOL = quality of life; NPRS = numeric pain rating scale; PROMIS = Patient Reported Outcomes Measurement Information System; GPH = Global Physical Health subscale; GMH = Global Mental Health subscale 


\section{Outcomes}

Primary

The KOOS has demonstrated validity, reliability, and responsiveness ${ }^{[34]}$ in assessing patient reported outcomes over time in those with degenerative knee conditions. The scale consists of 5 subscales (i.e., pain, symptoms, function in activities of daily living, function in sport and recreation, and knee-related quality of life) developed to assess change over time in those with primary OA or knee injuries resulting in post-traumatic $\mathrm{OA}^{[34]}$. A change in 10 points is considered clinically important ${ }^{[34]}$. Scores are reported on a scale of 0-100 with 100 representing the best possible score.

\section{Secondary}

The 11-point NPRS is commonly used to assess the level and change of patient reported pain over time. Pain is rated from 0 to 10 with zero representing 'no pain' and 10 representing 'worst imaginable pain' ${ }^{[35]}$. A 2-point or $30-33 \%$ reduction has been established as a clinically important difference in populations with chronic musculoskeletal pain, including knee $\mathrm{OA}^{[35,36]}$.

The Patient Reported Outcomes Measurement Information System (PROMIS $®$ ) Global Health scale v1.1 contains 10 questions spanning patient reported ratings of physical health, physical function, fatigue, pain, mental health, emotional distress, social health, and overall quality of life ${ }^{[37]}$. The PROMIS Scale v1.1 - Global Health produces two subscale scores: Global Physical Health (GPH) and Global Mental Health (GMH). Each subscale produces a raw score that is converted to a $\mathrm{T}$ score such that an average patient in the United States would have a subscale $\mathrm{T}$ score of 50 with a standard deviation of 10 points $^{[38]}$. Each scale has been recommended as a summary depiction of the physical and mental health of a patient ${ }^{[37]}$ and has been used in other conditions ${ }^{[39,40]}$, including knee arthroscopy ${ }^{[41]}$. Interestingly, lower GPH scores are associated with higher levels of healthcare utilization ${ }^{[42]}$.

\section{Sample}

A total of 17 patients were randomized to the BMAC group, and 15 patients were randomized to the HA group. Two patients in the BMAC group withdrew prior to the treatment intervention. Therefore, 15 patients were treated with BMAC and PRP during a single encounter, while 15 patients were treated with a single injection of the active comparator, Gel-One ${ }^{\circledR}$ Cross-Linked Hyaluronate. A sample size of 30 total patients undergoing the treatment intervention was established based on the power calculation $(\alpha=0.05, \beta=0.20)$ of a previous study comparing allogeneic bone marrow MSCs to hyaluronic acid in 30 patients with knee osteoarthritis ${ }^{[28]}$ and a preceding pilot study ${ }^{[43]}$. The primary outcome tool used in the study by Vega et al. has been demonstrated to have similar effect sizes at 6 and 12 months and similar smallest detectable differences compared to the KOOS scale in two different populations with knee-related deficits $^{[34,44]}$.
Blinding

The principal investigator, who performed all interventions, and study staff were both blinded to the randomization schedule except for the biostatistician generating the randomization list who was not involved in recruitment, enrollment, patient care activity, or data collection. The study team member meeting with patients at followup to collect patient reported outcomes was blinded to treatment allocation throughout the duration of the study.

\section{Statistical Methods}

All subjects who were assigned to treatment were included in the analysis. Descriptive statistics were used to summarize the characteristics of participants by group membership. Specifically, chi square tests were used to compare differences in categorical variables, and t-tests were used to compare differences in continuous variables between groups. For the main analyses to compare improvements in KOOS subscale scores, NPRS scores and PROMIS subscale scores, generalized estimating equations were used with an independent correlation, identity link and normal family. Models were fit using main effects for group and time, and a group-time interaction term to compare differences in mean scores over time and between groups. The alpha value was set at $\mathrm{p}<0.05$. All analyses were completed using Stata version 14 (StataCorp 2015).

\section{Results}

Characteristics of trial participants are provided in Table 2. At baseline, the trial participants were similar in terms of demographics, clinical characteristics, and past medical history with a single exception of those who were in the HA group were more likely to have had previous physical therapy in the target knee $(\mathrm{p}=0.036)$. Patients in both groups also had similar KOOS subscale, NPRS and PROMIS scores prior to the start of the clinical trial.

Table 3 provides mean values for the main outcome measure scores over time for both the BMAC and the HA groups. Overall, significant improvements were seen following treatment with BMAC for all KOOS subscale scores. KOOS pain subscale scores for the BMAC group significantly improved at 3 months $(p=0.001), 6$ months $(\mathrm{p}<0.001)$ and 12 months $(\mathrm{p}<0.001)$ compared to baseline. KOOS pain scores improved by an average of 23.48 points $(95 \%$ CI: $14.85,32.12$ ) from a mean baseline score of 60.82 to a mean score of 84.31 at 12 months. Similarly, KOOS pain subscale scores significantly improved for the HA group at 3 months $(\mathrm{p}<0.001), 6$ months $(p=0.009)$ and 12 months $(p<0.013)$ compared to baseline. Between baseline and 12 months, patients in the HA group improved their KOOS pain scores by an average of 12.67 points (95\% CI: 2.62 , 22.71) from a mean baseline score of 63.33 to a mean 12 month score of 76.00. Similar patterns were observed in improvements in KOOS symptoms, ADL, Sport and QOL scores over the course of the trial for both the BMAC and HA groups. There were no statistically significant differences in the rate of change in primary outcome scores between both groups. Figures 2 and 3 show the relative differences between the BMAC and HA groups, respectively, over time for the primary outcome scores. 
Table 3. Mean Primary Outcome Scores for BMAC and HA Groups at baseline, 3 months, 6 months and 12 months following treatment

\begin{tabular}{|c|c|c|c|c|c|c|c|c|}
\hline $\begin{array}{l}\text { Outcome } \\
\text { Measure }\end{array}$ & Group & Time & $\mathbf{n}$ & Mean (SD) & $\begin{array}{c}\text { Mean Difference }{ }^{A} \\
(95 \% \text { CI })\end{array}$ & p-value ${ }^{A}$ & $\begin{array}{c}\text { Mean Difference }{ }^{B} \\
(95 \% \text { CI })\end{array}$ & p-value ${ }^{B}$ \\
\hline $\begin{array}{l}\text { KOOS } \\
\text { Pain }\end{array}$ & 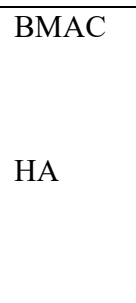 & $\begin{array}{l}\text { Baseline } \\
3 \text { mo } \\
6 \mathrm{mo} \\
12 \mathrm{mo} \\
\text { Baseline } \\
3 \mathrm{mo} \\
6 \mathrm{mo} \\
12 \mathrm{mo}\end{array}$ & $\begin{array}{l}17 \\
15 \\
14 \\
13 \\
15 \\
15 \\
14 \\
14\end{array}$ & $\begin{array}{l}60.82(15.05) \\
77.53(17.80) \\
80.86(15.68) \\
84.31(13.54) \\
63.33(17.72) \\
74.27(15.28) \\
75.86(14.23) \\
76.00(16.4)\end{array}$ & $\begin{array}{c}- \\
16.71(6.71,26.71) \\
20.03(10.71,29.36) \\
23.48(14.85,32.12) \\
- \\
10.93(5.15,16.71) \\
12.52(3.16,21.89) \\
12.67(2.62,22.71)\end{array}$ & $\begin{array}{c}- \\
0.001 \\
<0.001 \\
<0.001 \\
- \\
<0.001 \\
0.009 \\
0.013\end{array}$ & $\begin{array}{c}-2.51(-13.79,8.77) \\
5.78(-5.78,17.33) \\
7.51(-5.71,20.73) \\
10.82(-2.43,24.06)\end{array}$ & $\begin{array}{l}0.663 \\
0.327 \\
0.265 \\
0.109\end{array}$ \\
\hline $\begin{array}{l}\text { KOOS } \\
\text { Symptoms }\end{array}$ & 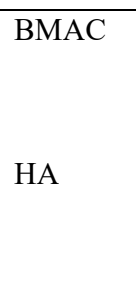 & $\begin{array}{l}\text { Baseline } \\
3 \mathrm{mo} \\
6 \mathrm{mo} \\
12 \mathrm{mo} \\
\text { Baseline } \\
3 \mathrm{mo} \\
6 \mathrm{mo} \\
12 \mathrm{mo}\end{array}$ & $\begin{array}{l}17 \\
15 \\
14 \\
13 \\
15 \\
15 \\
14 \\
14\end{array}$ & $\begin{array}{l}66.53(16.01) \\
83.93(13.42) \\
80.79(11.27) \\
84.54(9.05) \\
63.80(15.69) \\
79.27(15.41) \\
81.21(13.34) \\
77.00(16.23)\end{array}$ & $\begin{array}{c}- \\
14.00(4.38,23.63) \\
14.26(4.70,23.81) \\
18.01(10.29,25.72) \\
- \\
10.47(3.48,17.45) \\
12.41(5.45,19.37) \\
8.20(0.33,16.73)\end{array}$ & $\begin{array}{c}- \\
\mathbf{0 . 0 0 4} \\
\mathbf{0 . 0 0 3} \\
<\mathbf{0 . 0 0 1} \\
- \\
\mathbf{0 . 0 0 3} \\
<\mathbf{0 . 0 0 1} \\
0.06\end{array}$ & $\begin{array}{l}-2.27(-13.09,8.55) \\
3.54(-8.35,15.43) \\
1.84(-9.98,13.66) \\
9.81(-1.69,21.31)\end{array}$ & $\begin{array}{l}0.681 \\
0.560 \\
0.760 \\
0.095\end{array}$ \\
\hline $\begin{array}{l}\text { KOOS } \\
\text { ADL }\end{array}$ & HA & $\begin{array}{l}\text { Baseline } \\
3 \mathrm{mo} \\
6 \mathrm{mo} \\
12 \mathrm{mo} \\
\text { Baseline } \\
3 \mathrm{mo} \\
6 \mathrm{mo} \\
12 \mathrm{mo}\end{array}$ & $\begin{array}{l}17 \\
15 \\
14 \\
13 \\
15 \\
15 \\
14 \\
14\end{array}$ & $\begin{array}{c}68.59(17.98) \\
83.93(13.42) \\
86.71(11.92) \\
87.69(13.25) \\
70.13(18.34) \\
82.6(15.90) \\
85.07(12.54) \\
82.00(16.84)\end{array}$ & $\begin{array}{c}-- \\
15.35(5.10,25.59) \\
18.13(9.00,27.25) \\
19.10(9.52,28.68) \\
- \\
12.47(5.97,18.96) \\
14.94(5.98,23.90) \\
11.87(2.05,21.68)\end{array}$ & $\begin{array}{c}- \\
0.003 \\
<0.001 \\
<0.001 \\
- \\
<0.001 \\
0.001 \\
\mathbf{0 . 0 1 8}\end{array}$ & $\begin{array}{c}-1.55(-13.95,10.86) \\
2.88(-9.25,15.01) \\
3.19(-9.60,15.98) \\
7.24(-6.48,20.95)\end{array}$ & $\begin{array}{l}0.807 \\
0.642 \\
0.625 \\
0.301\end{array}$ \\
\hline $\begin{array}{l}\text { KOOS } \\
\text { Sport }\end{array}$ & BMAC & $\begin{array}{l}\text { Baseline } \\
3 \text { mo } \\
6 \mathrm{mo} \\
12 \mathrm{mo} \\
\text { Baseline } \\
3 \mathrm{mo} \\
6 \mathrm{mo} \\
12 \mathrm{mo}\end{array}$ & $\begin{array}{l}17 \\
15 \\
14 \\
13 \\
15 \\
15 \\
14 \\
14\end{array}$ & $\begin{array}{l}31.47(23.57) \\
60.93(27.25) \\
66.36(26.27) \\
70.54(28.66) \\
39.67(21.59) \\
69.73(25.19) \\
71.29(22.22) \\
65.71(24.87)\end{array}$ & $\begin{array}{c}- \\
29.46(13.02,45.91) \\
34.89(19.90,49.88) \\
39.07(22.00,56.13) \\
- \\
30.07(18.71,41.43) \\
31.62(16.41,46.82) \\
26.05(13.16,38.93)\end{array}$ & $\begin{array}{c}- \\
<0.001 \\
<0.001 \\
<0.001 \\
- \\
<0.001 \\
<0.001 \\
<0.001\end{array}$ & $\begin{array}{l}-8.20(-23.59,7.20) \\
-0.60(-20.59,9.39) \\
3.27(-18.08,24.62) \\
13.02(-8.36,34.40)\end{array}$ & $\begin{array}{l}0.297 \\
0.953 \\
0.764 \\
0.233\end{array}$ \\
\hline $\begin{array}{l}\text { KOOS } \\
\text { QOL }\end{array}$ & BMAC & $\begin{array}{l}\text { Baseline } \\
3 \text { mo } \\
6 \mathrm{mo} \\
12 \mathrm{mo} \\
\text { Baseline } \\
3 \mathrm{mo} \\
6 \mathrm{mo} \\
12 \mathrm{mo}\end{array}$ & $\begin{array}{l}17 \\
15 \\
14 \\
13 \\
15 \\
15 \\
14 \\
14\end{array}$ & $\begin{array}{l}36.18(18.50) \\
57.20(21.34) \\
61.14(18.83) \\
63.62(18.17) \\
38.47(15.94) \\
59.73(19.89) \\
62.64(17.10) \\
59.92(17.83)\end{array}$ & $\begin{array}{c}- \\
21.02(9.03,33.01) \\
24.97(14.51,35.42) \\
27.44(17.61,37.27) \\
- \\
21.27(11.10,31.43) \\
24.18(10.99,37.36) \\
21.46(8.33,34.60)\end{array}$ & $\begin{array}{c}- \\
\mathbf{0 . 0 0 1} \\
<\mathbf{0 . 0 0 1} \\
<\mathbf{0 . 0 0 1} \\
- \\
<0.001 \\
<\mathbf{0 . 0 0 1} \\
\mathbf{0 . 0 0 1}\end{array}$ & $\begin{array}{c}-2.29(-14.03,9.45) \\
-0.24(-15.96,5.48) \\
0.79(-16.04,17.62) \\
5.98(-10.43,22.38)\end{array}$ & $\begin{array}{l}0.702 \\
0.976 \\
0.927 \\
0.475\end{array}$ \\
\hline
\end{tabular}

A. P-values for 3 months, 6 months and 12 months compare scores within groups between the time point and baseline.

B. P-values for baseline compare the average difference in scores between BMAC and HA groups at baseline. P-values for 3 months, 6 months and 12 months compare scores between BMAC and HA groups between the time point and baseline. 


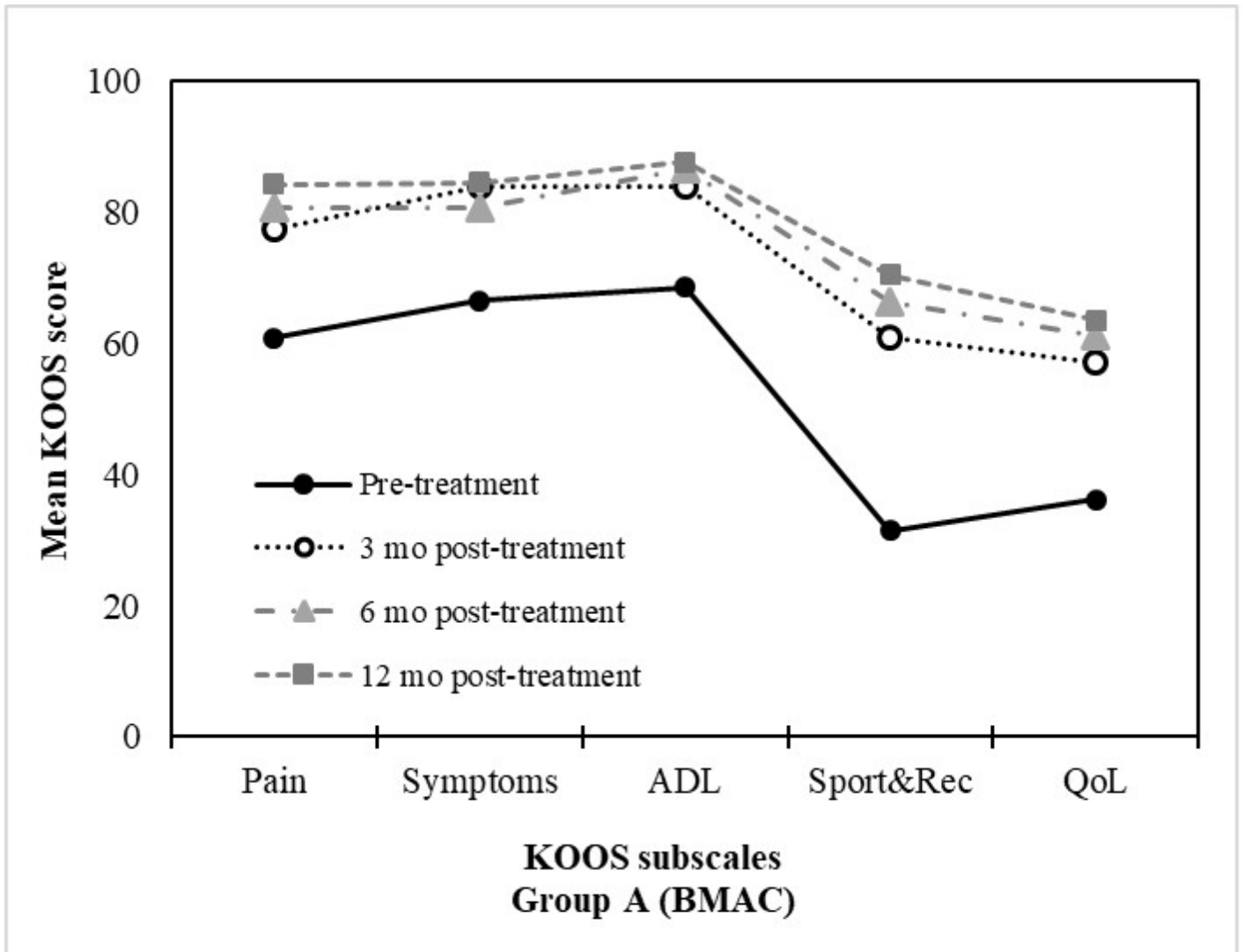

Figure 2: BMAC treatment resulted in improvements in KOOS profiles. Mean KOOS Scores (n=17) at the pre-treatment, 3 months, 6 months and 12 month assessments after treatment with BMAC.

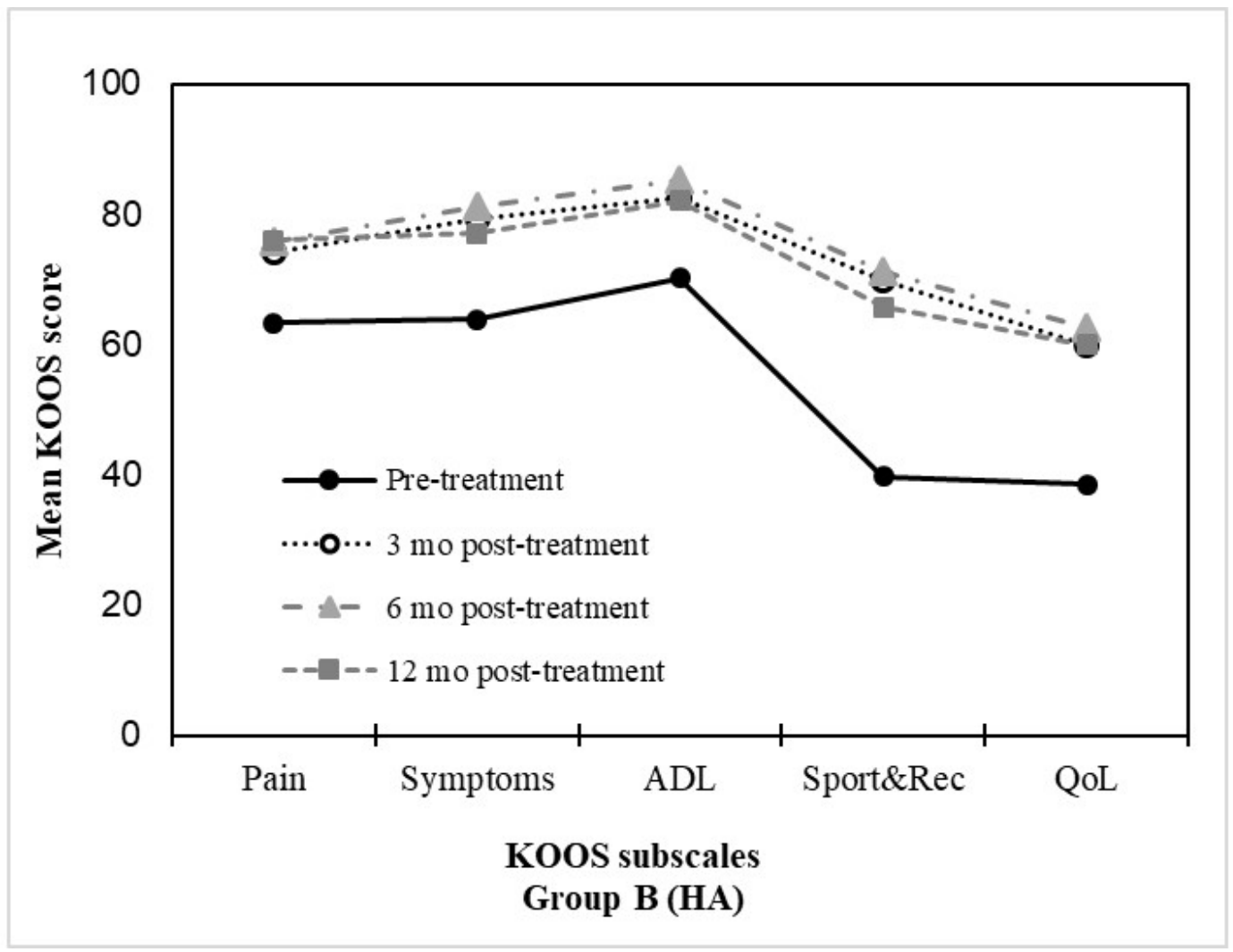

Figure 3: HA treatment resulted in improvements in KOOS profiles. Mean KOOS Scores $(n=15)$ at the pre-treatment, 3 months, 6 months and 12 month assessments after treatment with $H A$. 
NPRS scores significantly improved for both groups at 3, 6 and 12 months compared to baseline. Specifically, mean scores for the BMAC group improved from 4.59 at baseline to 1.46 at 12 months, while mean scores for the HA group improved from 4.20 at baseline to 2.64 at 12 months. The mean improvement difference between the two groups at 12 months relative to baseline was significant in favor of the BMAC group (mean difference $=-1.57$ (95\% CI: $-2.89,-0.25)$; $p=0.02)$. PROMIS GPH scores significantly improved for the BMAC group at $3(p=0.017), 6(p<0.001)$ and 12 months $(p=0.001)$, however the HA group only experienced improvements at 6 months relative to baseline $(p=0.04)$, and this difference subsided at 12 months $(p=0.077)$. PROMIS GMH scores improved at 3 months for the BMAC group ( $p=0.012$ ), however, this difference was no longer significant at 12 months $(p=0.959)$. The HA group did not experience any improvements in PROMIS GMH scores over the course of the trial. Similarly, there were no significant differences in the rate of improvement between the BMAC and HA groups over the course of the trial regarding the PROMIS GMH scores. Results are shown in Table 4. Figures 4-6 provide the relative differences between groups over time for secondary outcome scores.

Table 4. Improvements in BMAC and HA Group Secondary Outcome Scores Relative to Baseline

\begin{tabular}{|c|c|c|c|c|c|c|c|c|}
\hline $\begin{array}{l}\text { Outcome } \\
\text { Measure }\end{array}$ & Group & Time & $\mathbf{n}$ & Mean (SD) & $\begin{array}{c}\text { Mean Difference } \\
(95 \% \text { CI })\end{array}$ & p-value ${ }^{A}$ & $\begin{array}{c}\text { Mean Difference } \\
(95 \% \mathrm{CI})\end{array}$ & p-value ${ }^{B}$ \\
\hline NPRS & BMAC & $\begin{array}{l}\text { Baseline } \\
3 \mathrm{mo} \\
6 \mathrm{mo} \\
12 \mathrm{mo} \\
\text { Baseline } \\
3 \mathrm{mo} \\
6 \mathrm{mo} \\
12 \mathrm{mo}\end{array}$ & $\begin{array}{l}17 \\
15 \\
14 \\
13 \\
15 \\
15 \\
14 \\
14\end{array}$ & $\begin{array}{l}4.59(1.84) \\
2.67(2.55) \\
2.14(2.18) \\
1.46(1.51) \\
4.20(1.70) \\
2.33(1.99) \\
2.43(1.55) \\
2.64(2.02) \\
\end{array}$ & $\begin{array}{c}- \\
-1.92(-3.27,-0.57) \\
-2.45(-3.60,-1.28) \\
-3.13(-3.96,-3.29) \\
\quad- \\
-1.87(-2.76,-0.97) \\
-1.77(-2.55,-0.99) \\
-1.56(-2.59,-0.53)\end{array}$ & $\begin{array}{c}- \\
0.005 \\
<0.001 \\
<0.001 \\
- \\
<\mathbf{0 . 0 0 1} \\
<\mathbf{0 . 0 0 1} \\
\mathbf{0 . 0 0 3}\end{array}$ & $\begin{array}{c}0.39(-0.82,1.59) \\
-0.05(-1.67,1.57) \\
-0.67(-2.07,0.73) \\
-1.57(-2.89,-0.25)\end{array}$ & $\begin{array}{l}0.528 \\
0.947 \\
0.345 \\
\mathbf{0 . 0 2 0}\end{array}$ \\
\hline $\begin{array}{l}\text { PROMIS } \\
\text { Physical }\end{array}$ & BMAC & $\begin{array}{l}\text { Baseline } \\
3 \mathrm{mo} \\
6 \mathrm{mo} \\
12 \mathrm{mo} \\
\text { Baseline } \\
3 \mathrm{mo} \\
6 \mathrm{mo} \\
12 \mathrm{mo}\end{array}$ & $\begin{array}{l}17 \\
15 \\
14 \\
13 \\
15 \\
15 \\
14 \\
14\end{array}$ & $\begin{array}{c}44.62(7.61) \\
49.24(6.51) \\
51.38(6.89) \\
49.38(4.72) \\
48.23(7.99) \\
48.82(14.16) \\
51.73(8.57) \\
51.49(9.38)\end{array}$ & $\begin{array}{c}- \\
4.62(0.84,8.41) \\
6.76(3.63,9.89) \\
4.77(1.99,7.54) \\
- \\
0.59(-3.76,4.94) \\
3.50(0.16,6.83) \\
3.26(-0.36,6.88)\end{array}$ & $\begin{array}{c}- \\
\mathbf{0 . 0 1 7} \\
<\mathbf{0 . 0 0 1} \\
\mathbf{0 . 0 0 1} \\
- \\
0.791 \\
\mathbf{0 . 0 4 0} \\
0.077\end{array}$ & $\begin{array}{c}-3.62(-8.95,1.72) \\
4.04(-1.73,9.80) \\
3.27(-1.31,7.84) \\
1.51(-3.05,6.07)\end{array}$ & $\begin{array}{l}0.184 \\
0.170 \\
0.162 \\
0.517\end{array}$ \\
\hline $\begin{array}{l}\text { PROMIS } \\
\text { Mental }\end{array}$ & BMAC & $\begin{array}{l}\text { Baseline } \\
3 \mathrm{mo} \\
6 \mathrm{mo} \\
12 \mathrm{mo} \\
\text { Baseline } \\
3 \mathrm{mo} \\
6 \mathrm{mo} \\
12 \mathrm{mo}\end{array}$ & $\begin{array}{l}17 \\
15 \\
14 \\
13 \\
15 \\
15 \\
14 \\
14\end{array}$ & $\begin{array}{c}51.88(5.02) \\
49.71(4.93) \\
51.87(6.19) \\
51.95(4.93) \\
51.90(9.36) \\
51.25(14.78) \\
54.14(7.86) \\
54.91(9.75)\end{array}$ & $\begin{array}{c}- \\
-2.18(-3.87,-0.48) \\
-0.01(-3.25,3.23) \\
0.07(-2.64,2.77) \\
- \\
-0.65(-5.13,5.83) \\
2.24(-0.54,5.03) \\
3.01(-0.40,6.42)\end{array}$ & $\begin{array}{c}- \\
\mathbf{0 . 0 1 2} \\
0.995 \\
0.959 \\
- \\
0.775 \\
0.114 \\
0.084\end{array}$ & $\begin{array}{l}-0.02(-5.23,5.19) \\
-1.52(-6.31,3.27) \\
-2.25(-6.53,2.02) \\
-2.94(-7.29,1.42)\end{array}$ & $\begin{array}{l}0.995 \\
0.533 \\
0.301 \\
0.187\end{array}$ \\
\hline
\end{tabular}

A .P-values for 3 months, 6 months and 12 months compare scores within group 2 between the time point and baseline.

B. P-values for baseline compare the average difference in scores between BMAC and HA groups at baseline. P-values for 3 months, 6 months and 12 months compare scores between BMAC and HA groups between the time point and baseline. 


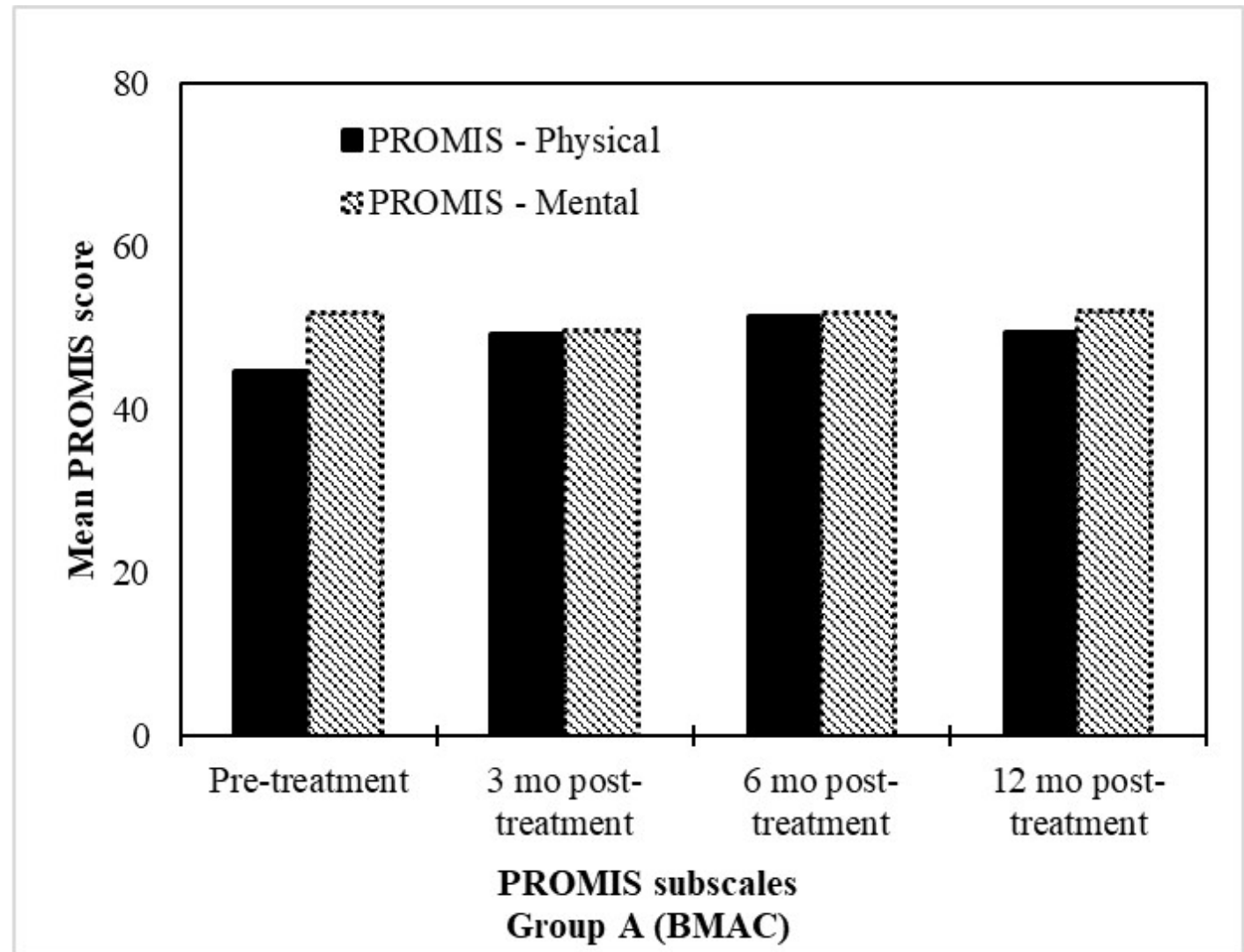

Figure 4: BMAC treatment resulted in improvements in PROMIS profiles. Mean PROMIS Scores ( $n=17)$ at the pre-treatment, 3 months, 6 months and 12 month assessments after treatment with BMAC.

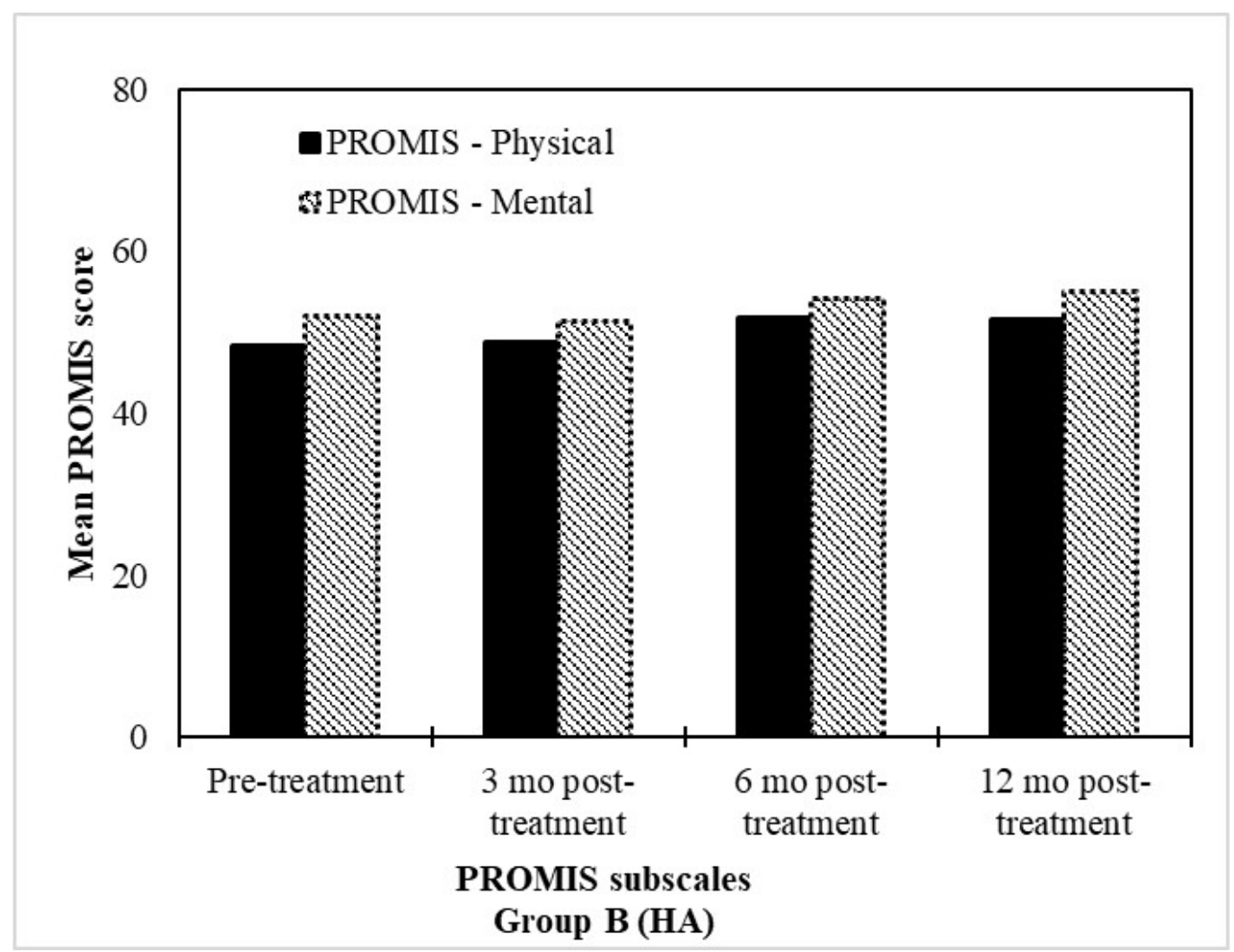

Figure 5: HA treatment resulted in improvements in PROMIS profiles. Mean PROMIS Scores (n=15) at the pre-treatment, 3 months, 6 months and 12 month assessments after treatment with $H A$. 


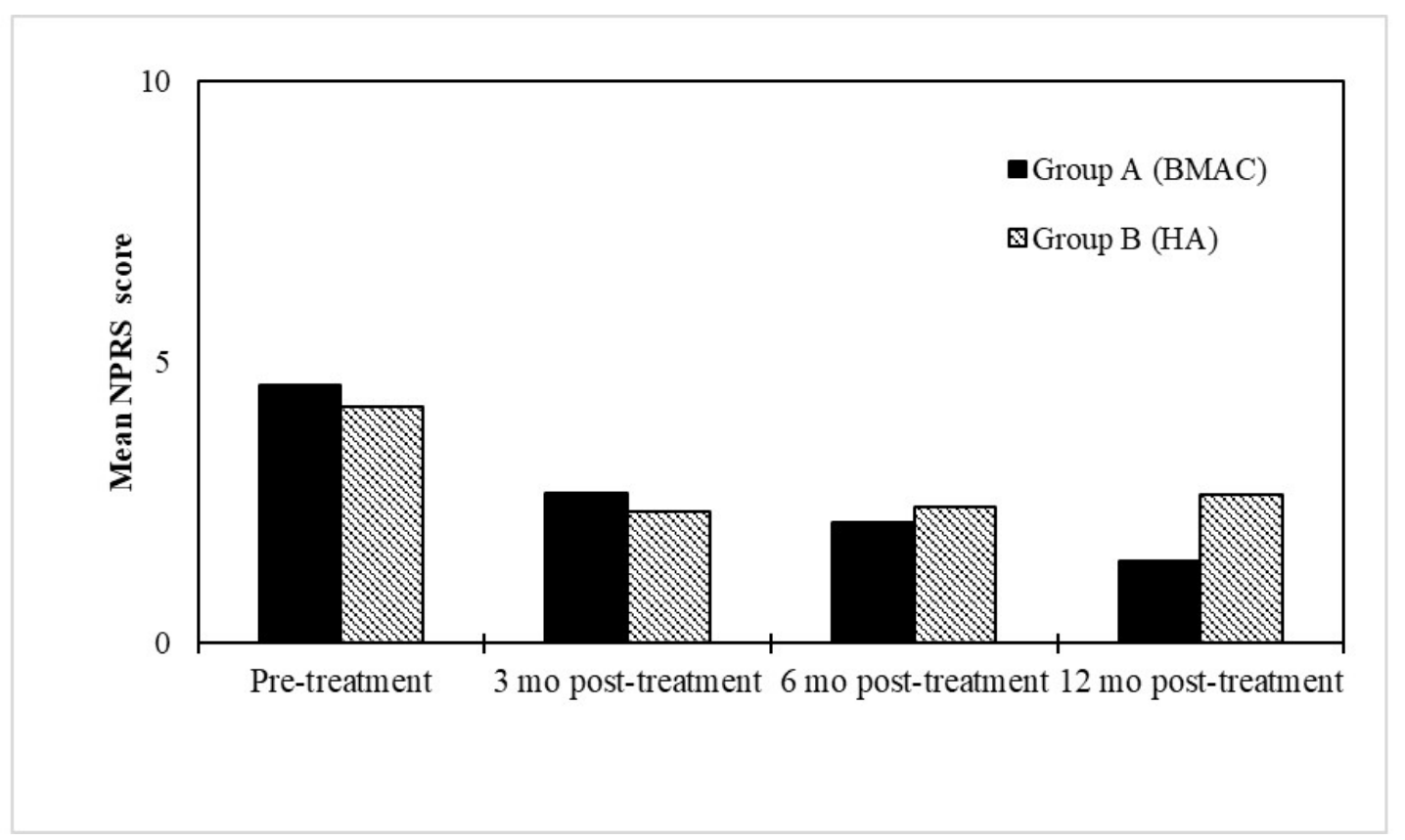

Figure 6: Both HA and BMAC treatment resulted in improvements in NPRS Subscale scores over time. BMAC group experienced greater benefits at 12 months ( $p<0.05$ ). Mean NPRS Scores at the pre-treatment, 3 months, 6 months and 12 month assessments after treatment with BMAC ( $n=17)$ or HA ( $n=15)$.

\section{Discussions}

In a prospective, single-blind, randomized controlled pilot study, patients with knee OA (KL grade 1-3) treated with either a single IA injection of BMAC and PRP or HA demonstrated clinically and statistically significant improvements in pain, function in activities of daily living, function in sport and recreation, and knee-related quality of life 1 year following treatment. While the magnitude of the change at 6 and 12 months for each of the KOOS subscales was consistently greater in the BMAC group, the difference did not reach statistical significance.

Two secondary outcomes were examined in the trial. The first secondary outcome was the score on the NPRS. While NPRS scores improved significantly across time for both groups, patients in the BMAC treatment arm experienced a greater improvement at the 12 month follow-up. The other secondary outcomes were scores on the global physical and mental health PROMIS assessments. It was observed that patients in the BMAC treatment arm experienced significant improvements from baseline on the physical scale after 12 months. Patients in the HA treatment arm did not experience significantly improved scores at 12 months. Patients in both treatment arms did not experience significant improvements in mental health scores from baseline through 12 months.

Regarding the primary outcome, the magnitude of change realized in patient reported pain, symptoms, function, and knee-related quality of life at 1 year following each treatment should not be understated. In this cohort of participants with a diagnosed chronic degenerative condition, clinically important improvements were noted at 1 year following treatment. In contrast, without intervention, we would logically expect no change or a slight functional decline over the same time period in a population with a chronic degenerative condition such as knee OA. This concept is supported by Øiestad et al. showing stable or slight declines in physical function year-to-year in two observational cohorts of individuals with incident knee
$\mathrm{OA}^{[45]}$. Thus, results of our study may illuminate the value in seeking maintenance treatment for this condition despite the lack of an identified treatment at this time to stop or reverse the disease state.

The results of this study draw similarities to a well-designed prospective, randomized controlled trial in which patients with bilateral symptomatic knee OA were treated with a BMAC IA injection in a single knee, while the other knee served as a saline injected control ${ }^{[32]}$. Patients were blinded to which knee was treated with a saline injection versus a BMAC injection. At the 3 and 6 month follow-up, patients reported significant improvements in pain in both knees. The knee joints treated with BMAC did not demonstrate superiority over the saline treated controls. In our study, we extended the follow-up to include a 12 month assessment. We hypothesized that both groups would see significant improvements in pain, function, and knee-related quality of life at 6 months; however, we expected differentiation at 12 months with superiority demonstrated in the BMAC treated cohort. Though there was a growing gap in the mean change scores in favor of the BMAC group at 12 months compared to earlier time points (see Table 2 for reference), this difference failed to reach statistical significance. Patient reported outcomes generally peaked at 6 months for the HA group compared to 12 months in the BMAC group. Future studies should consider extending the follow-up period to determine whether or not this pattern becomes clinically meaningful at a follow-up beyond 12 months.

Results of this study draw additional parallels from the literature regarding comparable improvements in pain and function following BMAC and PRP. Centeno et al. published registry data evaluating patient reported outcomes representing over 400 joints receiving autologous BMAC for knee OA. ${ }^{[46]}$ A small subset of the patients underwent PRP treatment following the initial BMAC IA injection. Overall, patients undergoing BMAC reported significant improvements in function and pain at 6 and 7 months, 
respectively ${ }^{[46]}$. The study was limited by the lack of a comparison group and a $33-36 \%$ response rate at the last follow-up time point limiting the ability to make determinations regarding the results compared to another treatment approach. Vega et al. extracted bone marrow MSCs from healthy donors and subsequently isolated and expanded the cells. The fifteen patients treated with an injection of the cultured bone marrow MSCs demonstrated significant improvements in pain and function at 6 and 12 months post-treatment. A comparison group receiving a single injection of HA had smaller, non-significant improvements in function; however, the group did report significant improvements in pain via the visual analog scale at 12 months. ${ }^{[28]} \mathrm{In}$ Vega et al., the extraction and expansion of cells is a key difference from our study in which the bone marrow withdrawal and injection occurred within the same encounter.

The previous study comparisons highlight a common theme across the literature base regarding orthobiologic therapy - a theme furthered by the results of this study. Studies specifically evaluating intra-articular application of $\mathrm{BMAC}^{[26-28,46]}$ or adipose-derived $\mathrm{MSCs}^{[29,30]}$ have demonstrated consistent improvement in pain and function at followup time points ranging from 6-24 months. However, the benefits of such treatments are interpreted cautiously as there are limitations in the current literature including heterogeneity of outcome measures ${ }^{[22]}$, heterogeneity of dosing ${ }^{[22]}$ and source of mesenchymal stem cells (i.e., bone marrow, adipose tissue, allo- vs. autograft), and a lack of large scale studies ${ }^{[24]}$. Two recent systematic reviews re-emphasize the above points. Delanois et al. concluded there is justification for the judicious use of bone marrow derived MSCs through careful clinical evaluation while acknowledging that coordinated treatment approaches and larger, blinded, placebo-based trials are essential ${ }^{[47]}$. Migliorini et al. concluded there is strong support that MSC therapies for knee OA improve clinical outcomes in key clinical measures ${ }^{[48]}$. As previously highlighted, a recent investigation reinforced significant clinical improvement resulting from both BMAC and PRP, however failed to differentiate between either as superior ${ }^{[31]}$. Ultimately, there remains a paucity of active comparator trials or placebo-based trials that do not involve expanded or otherwise manipulated cell components to result in a narrowed and recommended, standard clinical approach.

\section{Limitations}

This study has limitations to be noted. First, the sample size was relatively small. The smaller sample size may have limited the ability to detect between group differences, specifically at the 12 month follow-up as mean change scores between the groups for the primary outcome became more noticeable. Though the study included a small sample size, there were strong follow-up rates as $87 \%$ of patients in the BMAC group and $93 \%$ of patients in the HA group completed the 12 month follow-up.

Another limitation involved the bone marrow harvest technique. Since the initiation of this trial, there has been conjecture over the optimal technique of bone marrow harvest. Multiple harvest sites and varying the cannula depth between aspirations have been discussed as means of increasing the capture of desired cell populations. This study utilized single entry single depth technique and an open end aspiration needle, which could result in collecting a large volume of peripheral blood and fewer regenerative cells, with potential adverse impact on the clinical outcome ${ }^{[49-54]}$.
Our protocol and identified active comparator did not allow for patients or the treating physician to be blinded to group allocation. The BMAC and PRP procedure is more complex and distinctly different than the HA injection, which is a previously prepared solution. However, the protocol mitigated potential bias through use of a blinded outcomes assessor and a randomization schedule which was unknown to the research team with the exception of the biostatistician. The biostatistician did not have a role in patient recruitment, enrollment, treatment, or data collection.

We chose not to utilize imaging as an outcome measure, but rather only a standing anteroposterior, standing lateral, and standing posteroanterior bent knee radiograph to ensure an accurate knee OA diagnosis prior to enrollment. The details of MRI findings, including KL grade, have been previously shown to correlate poorly with clinical findings ${ }^{[55]}$. Thus, we opted to focus on patient reported outcomes that have been shown to correlate well to a patient's daily functional performance ${ }^{[56]}$.

\section{Conclusion}

This prospective, single-blind, randomized controlled pilot study demonstrated that patients in both treatment groups experienced clinically and statistically significant improvements across the KOOS subscales, including pain, symptoms (with the exception of the HA group), function in activities of daily living, function in sport and recreation, and knee-related quality of life at 12 months. In addition, patients treated with BMAC-PRP experienced a significant reduction in pain as measured through the NPRS at 12 months compared to the active control group. While orthobiologic options such as BMAC and PRP continue to show promise in the treatment of knee OA, there is a need for subsequent multi-center investigations with larger sample sizes, an extended follow-up, and a placebo-based control.

\section{References}

1. Hootman JM, Helmick CG, Barbour KE, Theis KA, Boring MA. Updated projected prevalence of self-reported doctor-diagnosed arthritis and arthritis-attributable activity limitation among US adults, 2015-2040. Arthritis \& Rheumatology. 2016;68(7):15821687.

2. The United States Bone and Joint Initiative. The burden of musculoskeletal diseases in the United States (BMUS) [Internet]. 4th ed. Rosemont, Illinois: The Initiative; 2019. Available from: www.boneandjointburden.org

3. Barbour KE, Helmick CG, Boring M, Brady TJ. Vital signs: prevalence of doctor-diagnosed arthritis and arthritis-attributable activity limitation-United States. Morb Mortal Wkly Rep. 2017;66:246-253.

4. Hochberg M, Cisternos M, Watkins-Castillo SL. Osteoarthritis [Internet]. [cited 2018 Sep 27]. Available from: http://boneandjointburden.org/fourth-edition/iiib10/osteoarthritis

5. Murphy L, Schwartz TA, Helmick CG, Renner JB, Tudor G, Koch G, Dragomir A, Kalsbeek WD, Luta G, Jordan JM. Lifetime risk of symptomatic knee osteoarthritis analysis and interpretation of data HHS Public Access. Arthritis Rheum [Internet]. 2008;59(9):1207-13. Available from: https://www.ncbi.nlm.nih.gov/pmc/articles/PMC4516049/pdf/nih ms-708148.pdf

6. White AG, Birnbaum HG, Janagap C, Buteau S, Schein J. Direct and indirect costs of pain therapy for osteoarthritis in an insured population in the United States. J Occup Environ Med. 2008;50(9):998-1005. 
7. Kolasinski SL, Neogi T, Hochberg MC, Oatis C, Guyatt G, Block J, Callahan L, Copenhaver C, Dodge C, Felson D, Gellar K, Harvey WF, Hawker G, Herzig E, Kwoh, CK, Nelson AE, Samuels J, Scanzello C, White D, Wise B, Altman RD, DiRenzo D, Fontanarosa J, Giradi G, Ishimori M, Misra D, Shah AA, Shmagel AK, Thoma LM, Turgunbaev M, Turner AS, Reston, J. 2019 american college of rheumatology/arthritis foundation guideline for the management of osteoarthritis of the hand, hip, and knee. Arthritis \& rheumatology. 2020;72(2):220-233.

8. Jevsevar DS, Brown GA, Jones DL, Matzkin EG, Manner PA, Mooar P, Schousboe JT, Stovitz S, Sanders JO, Bozic KJ, Goldberg MJ, Martin WR, Cummins DS, Donnelly P, Woznica A, Gross L. The American Academy of Orthopaedic Surgeons Evidence-Based Guideline on Treatment of Osteoarthritis of the Knee, 2nd Edition. J Bone Jt Surg. 2013;95(20):1885-6.

9. Bannuru RR, Osani MC, Vaysbrot EE, Arden NK, Bennell K, Bierma-Zeinstra SMA, Kraus VB, Lohmander LS, Abbott JH, Bhandari M, Blanco FJ, Espinosa R, Haugen IK, Lin J, Mandl LA, Moilanen E, Nakamura N, Snyder-Mackler L, Trojian T, Underwood M, McAlindon TE. Oarsi guidelines for the nonsurgical management of knee, hip, and polyarticular osteoarthritis. Osteoarthritis and cartilage. 2019;27(11):1578-1589.

10. Maradit Kremers H, Larson DR, Crowson CS, Kremers WK, Washington RE, Steiner CA, Jiranek WA, Berry DJ. Prevalence of total hip and knee replacement in the United States. J Bone Jt Surg Am Vol. 2014;97(17):1386-97.

11. Sloan M, N S. Projected volume of primary and revision total joint arthroplasty in the United States 2030-2060. In: American Academy of Orthopedic Surgeons [Internet]. New Orleans, LA; 2018. Available from: aaos-annualmeetingpresskit.org/2018/research-news/sloan-tjr/

12. Kurtz S, Ong K, Lau E, Mowat F, Halpern M. Projections of primary and revision hip and knee arthroplasty in the United States from 2005 to 2030. J Bone Jt Surg. 2007;89(4):780-5.

13. Agency for Healthcare Research and Quality. Nationwide Inpatient Sample (NIS), Healthcare Cost and Utilization Project (HCUP) [Internet]. 2014. Available from: http://www.ahrq.gov/research/data/hcup/index.html

14. Huddleston JI, Maloney WJ, Wang Y, Verzier N, Hunt DR, Herndon JH. Adverse events after total knee arthroplasty. A national medicare study. J Arthroplasty [Internet]. 2009;24(6 SUPPL.):95-100. Available http://dx.doi.org/10.1016/j.arth.2009.05.001

15. Wehling P, Evans C, Wehling J, Maixner W. Effectiveness of intra-articular therapies in osteoarthritis: a literature review. Therapeutic advances in musculoskeletal disease. 2017;9(8):183196.

16. Bannuru RR, Natov NS, Obadan IE, Price LL, Schmid CH, McAlindon TE. Therapeutic trajectory of hyaluronic acid versus corticosteroids in the treatment of knee osteoarthritis: A systematic review and meta-analysis. Arthritis Care Res. 2009;61(12):1704-11.

17. Miller LE, Fredericson M, Altman RD. Hyaluronic acid injections or oral nonsteroidal anti-inflammatory drugs for knee osteoarthritis: systematic review and meta-analysis of randomized trials. Orthopaedic journal of sports medicine. 2020;8(1):2325967119897909-2325967119897909.

18. Chevalier X, Jerosch J, Goupille P, Van Dijk N, Luyten FP, Scott DL, Bailleul F, Pavelka K. Single, intra-articular treatment with 6 $\mathrm{ml}$ hylan G-F 20 in patients with symptomatic primary osteoarthritis of the knee: A randomised, multicentre, doubleblind, placebo controlled trial. Ann Rheum Dis. 2010;69(1):1139 .

19. Varga Z, Sabzwari SRA, Vargova V. Cardiovascular risk of nonsteroidal anti-inflammatory drugs: an under-recognized public health issue. Cureus. 2017;9(4):1144.

20. Freitag J, Bates D, Boyd R, Shah K, Barnard A, Huguenin L, Tenen A. Mesenchymal stem cell therapy in the treatment of osteoarthritis: Reparative pathways, safety and efficacy - A review. BMC Musculoskelet Disord [Internet]. 2016;17(1):1-13. Available from: http://dx.doi.org/10.1186/s12891-016-1085-9
21. Mulvaney SW, Tortland P, Shiple B, Curtis K. Regenerative medicine options for chronic musculoskeletal conditions: A review of the literature. Endurance and Sports Medicine. 2018;Fall/Winter; 6-15.

22. Chahla J, Dean CS, Moatshe G, Pascual-Garrido C, Serra Cruz R, LaPrade RF. Concentrated bone marrow aspirate for the treatment of chondral injuries and osteoarthritis of the knee: A systematic review of outcomes. Orthop J Sport Med. 2016;4(1):1-8.

23. Pas HI, Winters M, Haisma HJ, Koenis MJ, Tol JL, Moen MH. Stem cell injections in knee osteoarthritis: a systematic review of the literature. Br J Sports Med. 2017;51(15):1125-33.

24. Yubo M, Yanyan L, Li L, Tao S, Bo L, Lin C. Clinical efficacy and safety of mesenchymal stem cell transplantation for osteoarthritis treatment: A meta-analysis. PLoS One. 2017;12(4):1-16.

25. Davidson PA, Bland DS, Henderson M. A systematic review of the treatment of knee osteoarthritis with intraarticular injection of mesenchymal stem cells. Curr Orthop Pract. 2018;29(6):590-6.

26. Lv X, Huang C, Yin Z, Hong B, Jiang H, Huang X. Effectiveness of autologous bone marrow mesenchymal stem cell transplant for knee osteoarthritis. Chin J Cell Stem Cell. 2015;5(2):28-32.

27. Orozco L, Munar A, Soler R, Alberca M, Soler F, Huguet M, Sentis J, Sanchez A, Garcia-Sancho J. Treatment of knee osteoarthritis with autologous mesenchymal stem cells: Two-year follow-up results. Transplantation. 2014;97(11):e66-8.

28. Vega A, Martín-Ferrero MA, Canto F Del, Alberca M, García V, Munar A, Orozco L, Soler R, Fuertes JJ, Huguet M, Sánchez A, García-Sancho J. Treatment of knee osteoarthritis with allogeneic bone marrow mesenchymal stem cells: A randomized controlled trial. Transplantation. 2015;99(8):1681-90.

29. Jo CH, Lee YG, Shin WH, Kim H, Chai JW, Jeong EC, Kim JE, Shim H, Shin JS, Shin IS, Ra JC, Oh S, Yoon KS. Intra-articular injection of mesenchymal stem cells for the treatment of osteoarthritis of the knee: A proof-of-concept clinical trial. Stem Cells. 2014;32(5):1254-66.

30. Jo CH, Chai JW, Jeong EC, Oh S, Shin JS, Shim H, Yoon KS. Intra-articular Injection of Mesenchymal Stem Cells for the Treatment of Osteoarthritis of the Knee: A 2-Year Follow-up Study. Am J Sports Med. 2017;45(12):2774-83.

31. Anz AW, Hubbard R, Rendos NK, Everts PA, Andrews JR, Hackel JG. Bone marrow aspirate concentrate is equivalent to platelet-rich plasma for the treatment of knee osteoarthritis at 1 year: a prospective, randomized trial. Orthopaedic journal of sports medicine. 2020;8(2):23259671199009582325967119900958

32. Shapiro SA, Kazmerchak SE, Heckman MG, Zubair AC, O'Connor MI. A prospective, single-blind, placebo-controlled trial of bone marrow aspirate concentrate for knee osteoarthritis. Am J Sports Med. 2017;45(1):82-90.

33. Harris PA, Taylor R, Thielke R, Payne J, Gonzalez N, Conde JG. Research Electronic Data Capture (REDCap) - A metadata-driven methodology and workflow process for providing translational research informatics support. J Biomed Inf. 2009;42(2):377-81.

34. Roos E, Lohmander L. The Knee injury and Osteoarthritis Outcome Score (KOOS): from joint injury to osteoarthritis. Health Qual Life Outcomes. 2003;(1):64.

35. Farrar JT, Young JP, LaMoreaux L, Werth JL, Poole RM. Clinical importance of changes in chronic pain intensity measured on an 11-point numerical pain rating scale. Pain. 2001;94(2):149-58.

36. Salaffi F, Stancati A, Silvestri C, Ciapetti A, Grassi W. Minimal clinically important changes in chronic musculoskeletal pain intensity measured in a numerical pain rating scale. Eur J Pain. 2004;8(4):283-91.

37. Hays RD, Bjorner JB, Revicki DA, Spritzer KL, Cella D. Development of physical and mental health summary scores from the patient-reported outcomes measurement information system (PROMIS) global items. Qual Life Res. 2009;18(7):873-80.

38. Global Health: A brief guide to the PROMIS Global Health Instruments [Internet]. NIH Toolbox. 2017. Available from: www.healthmeasures.net/index.php?option=com_content\&view $=$ article\&id $=180 \&$ Itemid $=994$ 
39. Kasturi S, Szymonifka J, Burket JC, Berman JR, Kirou KA, Levine AB, Sammaritano LR, Mandl LA. Feasibility, validity, and reliability of PROMIS global health short form in outpatients with systemic lupus erythematosus. J Rheumatol. 2018;45(3):397-404.

40. Katzan IL, Lapin B. PROMIS GH (Patient-reported outcomes measurement information system global health) scale in stroke a validation study. Stroke. 2018;49(1):147-54.

41. Oak SR, Strnad GJ, Bena J, Farrow LD, Parker RD, Jones MH, Spindler KP. Responsiveness comparison of the EQ-5D, PROMIS Global Health, and VR-12 questionnaires in knee arthroscopy. Orthop J Sport Med. 2016;4(12):1-7.

42. Blumenthal KJ, Chang Y, Ferris TG, Spirt JC, Vogeli C, Wagle N, Metlay JP. Using a self-reported global health measure to identify patients at high risk for future healthcare utilization. J Gen Intern Med. 2017;32(8):877-82.

43. Orozco L, Munar A, Soler R, Alberca M, Soler F, Huguet M, Sentís J, Sánchez A, García-Sancho J. Treatment of knee osteoarthritis with autologous mesenchymal stem cells: A pilot study. Transplantation. 2013;95(12):1535-41.

44. Van De Graaf VA, Wolterbeek N, Scholtes VAB, Mutsaerts ELAR, Poolman RW. Reliability and validity of the IKDC, KOOS, and WOMAC for patients with meniscal injuries. Am J Sports Med. 2014;42(6):1408-16.

45. Øiestad BE, White DK, Booton R, Niu J, Zhang Y, Torner J, Lewis CE, Nevitt M, L M, Felson DT. Longitudinal course of physical function in people with symptomatic knee osteoarthritis: Data from the Multicenter Osteoarthritis Study and the Osteoarthritis Initiative. Arthritis Care Res. 2016;68(3):325-31.

46. Centeno C, Pitts J, Al-Sayegh H, Freeman M. Efficacy of Autologous Bone Marrow Concentrate for Knee Osteoarthritis with and without Adipose Graft. Biomed Res Int. 2014;2014.

47. Delanois RE, Etcheson JI, Sodhi N, Henn RF, Gwam CU, George NE, Mont MA. Biologic therapies for the treatment of knee osteoarthritis. J Arthroplasty [Internet]. 2019;34(4):801-13. Available from: https://doi.org/10.1016/j.arth.2018.12.001
48. Migliorini F, Rath B, Colarossi G, Driessen A, Tingart A, Niewiera M, Eschweiler J. Improved outcomes after mesenchymal stem cells injections for osteoarthritis: Results at 12-months follow-up: a systematic review of the literature. Arch Orthop Trauma Surg. 2019.

49. Oliver K, Awan T, Bayes M. Single- versus multiple-site harvesting techniques for bone marrow concentrate: evaluation of aspirate quality and pain. Orthopaedic journal of sports medicine. 2017;5(8):2325967117724398-2325967117724398.

50. Peters AE, Watts AE. Biopsy needle advancement during bone marrow aspiration increases mesenchymal stem cell concentration. Frontiers in veterinary science. 2016;3:23-23.

51. Murphy MB, Terrazas JA, Buford DA. Bone marrow concentrate and platelet-rich plasma acquisition and preparation: why technique matters. Techniques in regional anesthesia and pain management. 2015;19(1-2):19-25.

52. Hernigou P, Homma Y, Flouzat Lachaniette $\mathrm{CH}$, et al. Benefits of small volume and small syringe for bone marrow aspirations of mesenchymal stem cells. International orthopaedics. 2013;37(11):2279-2287.

53. Scarpone M, Kuebler D, Chambers A, et al. Isolation of clinically relevant concentrations of bone marrow mesenchymal stem cells without centrifugation. Journal of translational medicine. 2019;17(1):10-10.

54. Friedlis MF, Centeno CJ. Performing a better bone marrow aspiration. Physical medicine and rehabilitation clinics of north america. 2016;27(4):919-939.

55. Link T, Steinbach L, Ghoush S, Ries M, Lu Y, Lane N, Majumdar S. Osteoarthritis: MR imaging findings in different stages of disease and correlation with clinical findings. Radiology. 2003;226(2):373-81.

56. Sabirli F, Parker N, Bugdayci D. The relationship between knee injury and osteoarthritis outcome score (KOOS). Rheumatol Int Clin Exp Investig. 2013;33(10):2691-4. 


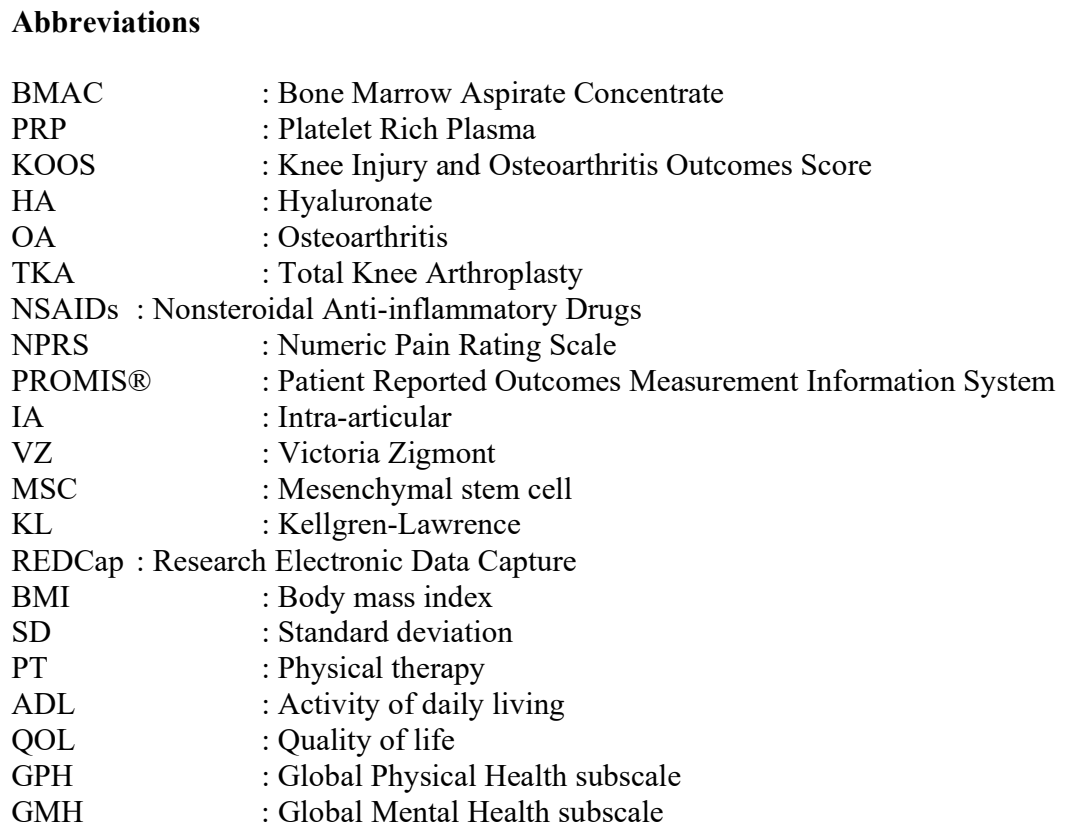

\section{Potential Conflicts of Interests}

None

\section{Acknowledgments}

Judy M. Opalek, PhD and Tamara McMath, MPH, both of whom were affiliated with the OhioHealth Research Institute (OhioHealth Corporation, Columbus, Ohio - USA) at the time of their contributions regarding protocol review and guidance; OhioHealth Value Development Review Committee (OhioHealth Corporation, Columbus, Ohio - USA) for financial support.

\section{Sponsor/Grants}

OhioHealth Value Development Review Committee, 3430 OhioHealth Parkway, Columbus, OH, USA, 43202

\section{Corresponding Author}

Joseph J. Ruane, OhioHealth McConnell Spine Sport and Joint Physicians, 3773 Olentangy River Road, Columbus, OH, USA, Zip code: 43214; Email: joseph.ruane@ohiohealth.com | jruane83@gmail.com 